\title{
Colonization of lettuce rhizosphere and roots by tagged Streptomyces
}

\author{
Maria Bonaldi ${ }^{\dagger}$, Xiaoyulong Chen $^{+}$, Andrea Kunova ${ }^{+}$, Cristina Pizzatti $^{+}$, Marco Saracchi and \\ Paolo Cortesi*
}

Department of Food, Environmental and Nutritional Sciences, University of Milan, Milan, Italy

\author{
Edited by: \\ Aurelio Ciancio, Consiglio Nazionale \\ delle Ricerche - Istituto per la \\ Protezione Sostenibile delle Piante, \\ Italy

\section{Reviewed by:} \\ Elena Prats, Spanish National \\ Research Council, Spain \\ Stephane Compant, Austrian Institute \\ of Technology $\mathrm{GmbH}$, Austria

\section{*Correspondence:} \\ Paolo Cortesi, Department of Food, \\ Environmental and Nutritional \\ Sciences, University of Milan, Via \\ Giovanni Celoria, 220133 Milano, Italy \\ e-mail:paolo.cortesi@unimi.it \\ ${ }^{\dagger}$ These authors have contributed \\ equally to this work.
}

\begin{abstract}
Beneficial microorganisms are increasingly used in agriculture, but their efficacy often fails due to limited knowledge of their interactions with plants and other microorganisms present in rhizosphere. We studied spatio-temporal colonization dynamics of lettuce roots and rhizosphere by genetically modified Streptomyces spp. Five Streptomyces strains, strongly inhibiting in vitro the major soil-borne pathogen of horticultural crops, Sclerotinia sclerotiorum, were transformed with plJ8641 plasmid harboring an enhanced green fluorescent protein marker and resistance to apramycin. The fitness of transformants was compared to the wild-type strains and all of them grew and sporulated at similar rates and retained the production of enzymes and selected secondary metabolites as well as in vitro inhibition of S. sclerotiorum. The tagged ZEA17l strain was selected to study the dynamics of lettuce roots and rhizosphere colonization in non-sterile growth substrate. The transformed strain was able to colonize soil, developing roots, and rhizosphere. When the strain was inoculated directly on the growth substrate, significantly more t-ZEA17I was re-isolated both from the rhizosphere and the roots when compared to the amount obtained after seed coating. The re-isolation from the rhizosphere and the inner tissues of surface-sterilized lettuce roots demonstrated that t-ZEA17I is both rhizospheric and endophytic.
\end{abstract}

\section{Keywords: biocontrol, Lactuca sativa, Sclerotinia sclerotiorum, streptomycetes, rhizosphere competence}

\section{INTRODUCTION}

Roots anchor plants in soil, provide uptake of water and nutrients, and mediate numerous interactions with soil organisms. The interface between roots and soil - where most of these interactions take place - is called rhizosphere. This narrow and specific zone is distinct from bulk soil in terms of nutrient availability, $\mathrm{pH}$ and presence of a wide variety of microorganisms and invertebrates attracted and influenced by root exudates and rhizodeposits (Hinsinger et al., 2009; Compant et al., 2010; Philippot et al., 2013). Many microbes present in rhizosphere have neutral effect on plants, while others positively or negatively affect host development and health via complex interactions, which we are only beginning to understand (Raaijmakers et al., 2009; Compant et al., 2010; Glick, 2012). Some microorganisms are deleterious as they compete with plants for nutrients or cause disease (soil borne plant pathogens), while others support their hosts by mobilizing nutrients, stimulating growth, and increasing yield or reducing biotic and abiotic stresses, such as mycorrhizal fungi and plant growth promoting bacteria (PGPB; Compant et al., 2010; Aeron et al., 2011; Smith and Smith, 2011).

Plant growth promoting bacteria are gaining more and more attention in modern agriculture, where sustainable and environmentally friendly strategies of crop cultivation increasingly rely on their use as biofertilizers, phytostimulants, or biopesticides. They employ several mechanisms to improve the plant growth, such as synthesis of phytohormones, nitrogen fixation and increasing availability of nutrients by production of siderophores and solubilization of phosphates (Lugtenberg et al., 2002; Compant et al., 2010). Furthermore, special attention is dedicated to biological control agents (BCAs), a group of microorganisms producing a wide variety of biologically active molecules potentially able to inhibit plant pathogens. Antagonism is one of the most common modes of action; here the BCA inhibits or kills pathogens via production of diffusible or volatile antimicrobial compounds and cell wall degrading enzymes. Antagonism is widespread in Bacillus, Pseudomonas, and Streptomyces spp., from which a wide range of biologically active secondary metabolites were isolated (Raaijmakers etal., 2002; Compant etal., 2005).

Despite the optimal performance at laboratory-scale screening tests, PGPB often fail to demonstrate their potential or show inconsistent results in greenhouse and field trials. This variable performance may have different causes, such as reduced or delayed expression of bioactive molecules in the presence of competing microorganisms or lower rhizosphere competence, i.e., poor colonization of root tissues and rhizosphere of the host plant (Lugtenberg et al., 2001; Compant et al., 2010; Ghirardi et al., 2012). To overcome these obstacles, it is essential to understand how PGPB interact with the host plant and with other microorganisms present in soil. Several studies have demonstrated better plant protection when bioactive Pseudomonas spp. strains with improved rhizosphere-competence were used (Ghirardi et al., 2012). In recent years, several characters essential for rhizosphere colonization were identified in Pseudomonas 
spp. (Latour et al., 2003; Lugtenberg and Kamilova, 2009), however, similar studies are missing for other beneficial genera of bacteria.

One of such genera is Streptomyces, filamentous Gram-positive bacteria commonly inhabiting soil and rhizosphere and renowned for the production of a variety of bioactive secondary metabolites (Loria et al., 2006; Hopwood, 2007). They have been largely exploited in pharmaceutical industry since 1940s (Watve et al., 2001; Lucas et al., 2013), whereas only a few have been developed as commercial products for plant application in agriculture (Yuan and Crawford, 1995; Minuto etal., 2006; Berg, 2009). Streptomycetes have been long considered simply as free-living soil inhabitants, but recently the importance of their complex interactions with plants and other organisms is being uncovered (Seipke etal., 2012). Some of them, such as S. scabies or S. turgidiscabies, are plant pathogens with broad host range, causing important economic losses especially on tap root and tuber crops, such as potatoes, sweet potatoes, carrots, or beet (Loria et al., 2006; Seipke et al., 2012). On the contrary, many others establish beneficial relationships with host plants as endophytes (Sardi et al., 1992; Coombs and Franco, 2003; Cao et al., 2004). Auxin production was described for endophytic and free living Streptomyces in rhizosphere (Coombs et al., 2004; Khamna et al., 2009), while S. lydicus augmented the nodulation by Rhizobium species in pea plants, increasing iron and molybdenum assimilation as well as root growth (Tokala et al., 2002; Seipke et al., 2012).

Several markers have been developed and adopted to study localization and quantification of PGPB in the rhizosphere; among these, antibiotic resistance has been widely used (Prosser, 1994; Gamalero et al., 2003). Because many of soil microorganisms produce a variety of different antibiotics, it is necessary to determine the specificity of the antibiotic marker selected for the identification of PGPB before its use. Currently, fluorescent markers are gaining increasing popularity for colonization studies ( $\mathrm{Lu}$ et al., 2004; Cao et al., 2011; Krzyzanowska et al., 2012). Various derivatives of green fluorescent protein (GFP) have been engineered to increase the fluorescence and to overcome the variable expression of the original marker in different species (Errampalli et al., 1999; Gamalero et al., 2003). Enhanced GFP (EGFP) contains numerous silent nucleotide changes in comparison to GFP to maximize its expression in mammalian cells (Haas et al., 1996), and was adopted for use in Streptomyces spp., which have a similar codon usage (Sun et al., 1999).

Green fluorescent protein has been utilized to study PGPB colonization of roots and rhizosphere in sterile conditions (Coombs and Franco, 2003; Weyens et al., 2012). These studies provide a basic understanding of the interactions between PGPB and the host plant, but they do not consider the complex interactions in vivo. In non-sterile conditions with high microbial diversity, PGPB have to compete with other microorganisms present in the rhizosphere, and in some cases the competition reduced the colonization ability of PGPB (Cao et al., 2011; Hohmann et al., 2012; Weyens etal., 2012). Moreover, the activity and the fitness of the transformed strain need to be controlled following the transformation, as it has been observed that the presence of the transgene may interfere with the biological activity of the studied organism (Nigro et al., 1999; Lübeck et al., 2002; Weyens et al., 2012).

The objective of this work was to get insight into the localization and colonization of a genetically modified Streptomyces strain, selected as potential BCA, in lettuce roots and rhizosphere. First, we compared the fitness of the transformed and the corresponding wild-type strains, then we studied the colonization dynamics of the most promising transformed strain in rhizosphere and roots of lettuce plants in non-sterile growth substrate. Finally, we compared the effect of two inoculation methods on the ability of the Streptomyces strain to differentially colonize rhizosphere and roots.

\section{MATERIALS AND METHODS TRANSFORMATION OF Streptomyces spp.}

Five Streptomyces strains, potential BCAs against Sclerotinia sclerotiorum, were used in this study: CX14W, CX16W, FT05W, SW06W, and ZEA17I. They were maintained at the Plant Pathology Laboratory, Department of Food, Environmental and Nutritional Sciences (DeFENS), University of Milan, and selected previously from a wide collection of actinomycetes isolated from roots of different plants (Sardi et al., 1992; Petrolini et al., 1996; Bonaldi et al., 2011, 2014). Escherichia coli strain ET12567 (harboring the helper plasmid pUZ8002), was provided by prof. Flavia Marinelli, University of Insubria, Italy, and was used as donor strain for conjugation. Plasmid pIJ8641, obtained from prof. Mervyn Bibb, John Innes Centre, UK, was maintained in E. coli strain DH5 $\alpha$. It carries the EGFP gene under the constitutive ermE promoter, an apramycin resistance marker $[a a c(3) I V]$, an oriT/RK2 region, and a lambda phage chromosomal integration sequence (IntC31; Sun et al., 1999). The strain S. coelicolor A3(2) was obtained from F. Marinelli, and used as a reference strain to evaluate transformation efficiency.

Plasmid pIJ8641 was transformed into the donor strain E. coli ET12567 (pUZ8002) by rubidium chloride method (Hanahan, 1983) and conjugated into recipient Streptomyces strains as previously described (Kieser et al., 2000). Prior to conjugation, the concentration of the E. coli donor strain ET12567 containing plasmid pIJ8641 was adjusted to $1 \times 10^{7} \mathrm{CFU} / \mathrm{mL}$. The ex-conjugants were selected on the basis of apramycin resistance. The conjugation efficiency was calculated as number of ex-conjugant colonies per number of recipient spores.

Genomic DNA of wild-type and transformed (t-) Streptomyces strains was extracted by the CTAB method (Kieser et al., 2000). The amplification of $16 \mathrm{~S}$ rDNA fragment (expected size $1500 \mathrm{bp}$ ) was used to evaluate the quality of DNA in all samples, using PCR primers fD1 (5'-AGAGTTTGATCCTGGCTCAG-3') and fD2 (5'-ACGGCTACCTTGTTACGACTT-3'; Weisburg et al., 1991), and the following thermal cycling conditions: initial denaturation at $94^{\circ} \mathrm{C}$ for $1 \mathrm{~min}, 30$ cycles of denaturation at $92^{\circ} \mathrm{C}$ for $45 \mathrm{~s}$, annealing at $56^{\circ} \mathrm{C}$ for $30 \mathrm{~s}$ and extension at $72^{\circ} \mathrm{C}$ for $2 \mathrm{~min}$, a final extension at $72^{\circ} \mathrm{C}$ for $5 \mathrm{~min}$. PCR primers rEGFPN (5' ${ }^{\prime}$ CTGGTCGAGCTGGACGGCGACG-3') and rEGFP-C (5' CACGAACTCCAGCAGGACCA TG-3') were designed to amplify the EGFP gene fragment (expected fragment size $700 \mathrm{bp}$ ), using the following thermal cycling conditions: initial denaturation at $94^{\circ} \mathrm{C}$ for $1 \mathrm{~min}, 30$ cycles of denaturation at $92^{\circ} \mathrm{C}$ for $45 \mathrm{~s}$, annealing at $60^{\circ} \mathrm{C}$ for $45 \mathrm{~s}$ and extension at $72^{\circ} \mathrm{C}$ for $2 \mathrm{~min}$, a final 
extension at $72^{\circ} \mathrm{C}$ for $2 \mathrm{~min}$. The DNA amplification was carried out using PCR thermal cycler (BioRad, USA), performed in a total volume of $25 \mu \mathrm{L}$ containing 30-50 ng DNA, $0.25 \mu \mathrm{M}$ each primer, $1 \mathrm{U} / \mu \mathrm{L}$ Go Taq DNA polymerase (Promega, USA), $5 \mu \mathrm{L}$ of $5 \mathrm{x}$ Go Taq buffer (Promega, USA), and $0.2 \mathrm{mM}$ of each dNTP. The PCR products were visualized under Gel Doc transilluminator (BioRad, USA) following electrophoresis in $1 \%(\mathrm{w} / \mathrm{v})$ agarose gel.

For microscopic observations, the transformed Streptomyces strains were inoculated on Czapek yeast extract agar (CZY; $35 \mathrm{~g} / \mathrm{L}$ Czapek-Dox Broth Difco, 2 g/L Yeast Extract Difco, 15 g/L agar). A microscopic cover slide was partially inserted in the medium at the edge of the inoculated strain under the $45^{\circ}$ angle to allow the strain to grow on the cover slide. The plates were incubated at $24^{\circ} \mathrm{C}$ for 5 days. Subsequently, cover slides were removed from the medium and observed by brightfield and epifluorescence microcopy using Olympus BX51 with the FITC filter set (467-498 nm excitation and 513-556 nm emission) to confirm the expression of EGFP in transformants.

\section{INHIBITION OF Sclerotinia sclerotiorum GROWTH IN VITRO}

The antagonistic activity of wild-type and transformed (t-) Streptomyces strains against $S$. sclerotiorum was determined by dual culture assay on CZY agar as described (Bonaldi et al., 2014). Briefly, $10 \mu \mathrm{L}$ of Streptomyces spore suspension $\left(1 \times 10^{7} \mathrm{CFU} / \mathrm{mL}\right)$ were inoculated on a $40 \mathrm{~mm}$ line two days prior to $S$. sclerotiorum inoculation. An agar-mycelium plug ( $5 \mathrm{~mm}$ diameter), obtained from the edge of an actively growing colony of $S$. sclerotiorum grown on Malt Extract Agar (MEA; 20 g/L Malt Extract, Difco, and $15 \mathrm{~g} / \mathrm{L}$ agar), was placed at $25 \mathrm{~mm}$ distance from the growing Streptomyces colony and the plates were incubated for $72 \mathrm{~h}$ at $24^{\circ} \mathrm{C}$. Plates inoculated with S. sclerotiorum only were used as a control. The antagonistic activity was determined by calculating the percentage of growth inhibition of S. sclerotiorum compared to the control. The experiment was repeated twice in three replicates.

\section{MYCELIUM GROWTH AND SPORULATION}

The mycelium growth curve of transformed and wild-type strains was determined daily as follows: $20 \mu \mathrm{L}$ of Streptomyces spore suspension $\left(1 \times 10^{7} \mathrm{CFU} / \mathrm{mL}\right)$ were transferred into a $50 \mathrm{~mL}$ tube containing $20 \mathrm{~mL}$ of $\mathrm{CZY}$ broth, and incubated at $30^{\circ} \mathrm{C}$ with 200 rpm constant shaking for 8 days. Each day, $2 \mathrm{~mL}$ of liquid culture were removed and spun at $10600 \mathrm{~g}$ for $10 \mathrm{~min}$ and the dry weight of the pellet was repeated twice in three replicates and expressed in $\mathrm{g} / \mathrm{L}$.

The sporulation of the strains was measured by plating $1 \mathrm{~mL}$ of spore suspension $\left(1 \times 10^{7} \mathrm{CFU} / \mathrm{mL}\right)$ on a CZY agar plate and determining the number of spores produced after 6 days of incubation at $30^{\circ} \mathrm{C}$ (Grantcharova et al., 2005). Five $\mathrm{mL}$ of sterile water were added to the Petri plate and the surface of colonies was gently scraped to release the newly formed spores (Kieser et al., 2000). The spore suspension was filtrated through two layers of sterile gauze and the spore concentration $(\mathrm{CFU} / \mathrm{mL})$ was quantified by plating serial dilutions of the spore suspension and counting the number of colonies grown after 4 days of incubation at $30^{\circ} \mathrm{C}$. The experiment was repeated twice in three replicates.

\section{PRODUCTION OF SECONDARY METABOLITES Siderophore production}

Ten milliliter of Fe-free Czapek solution (300 g/L NaNO $3,50 \mathrm{~g} / \mathrm{L}$ $\mathrm{KCl}, 50 \mathrm{~g} / \mathrm{L} \mathrm{MgSO}_{4} \cdot 7 \mathrm{H}_{2} \mathrm{O}$ ) were mixed with $15 \mathrm{~g} / \mathrm{L}$ agar, $30 \mathrm{~g} / \mathrm{L}$ sucrose, $1 \mathrm{~g} / \mathrm{L} \mathrm{K}_{2} \mathrm{HPO}_{4}$, and $5 \mathrm{~g} / \mathrm{L}$ yeast extract to prepare the Fe-free Czapek agar medium. Ten microliter of Streptomyces spore suspension $\left(1 \times 10^{7} \mathrm{CFU} / \mathrm{mL}\right)$ were inoculated in the center of a Fe-free Czapek agar plate and incubated at $30^{\circ} \mathrm{C}$ for two weeks. Subsequently, the Streptomyces colony was overlaid by $15 \mathrm{~mL}$ of the Chrome azurol S (CAS) agar (Schwyn and Neilands, 1987; PerezMiranda et al., 2007). The siderophore production was determined as color change in the overlay medium (from blue to orange) after $24 \mathrm{~h}$ of incubation at room temperature. The experiment was repeated twice in three replicates.

\section{Chitinase production}

The colloidal chitin and the colloidal chitin agar were prepared as described previously (Saima et al., 2013). Ten microliter of Streptomyces spore suspension $\left(1 \times 10^{7} \mathrm{CFU} / \mathrm{mL}\right)$ were inoculated in the center of colloidal chitin agar plate (chitin as single carbon sources) as a $40 \mathrm{~mm}$ line and incubated at $30^{\circ} \mathrm{C}$ for 10 days. The production of chitinase was determined based on the presence of a clear hydrolysis zone on the agar plate below the colony. The experiment was repeated twice in three replicates.

\section{Phosphate solubilization}

The phosphate solubilization activity of the Streptomyces strains was assessed using a plate assay with National Botanical Research Institute's Phosphate (NBRIP) medium (Nautiyal, 1999), in which $\mathrm{Ca}_{3}\left(\mathrm{PO}_{4}\right)_{2}$ is the only phosphate source. Ten microliter of Streptomyces spore suspension $\left(1 \times 10^{7} \mathrm{CFU} / \mathrm{mL}\right)$ were inoculated in the center of a NBRIP-medium Petri plate and incubated at $30^{\circ} \mathrm{C}$ for 2 weeks. The phosphate solubilization was determined based on the presence of a clear hydrolysis zone on the agar plate below the colony. The test was repeated twice in three replicates.

\section{Indole-3-acetic acid (IAA) synthesis}

The IAA production was determined as described previously (Bric et al., 1991; Bano and Musarrat, 2003). In brief, $10 \mu \mathrm{L}$ of Streptomyces spore suspension $\left(1 \times 10^{7} \mathrm{CFU} / \mathrm{ml}\right)$ were incubated with constant shaking at $5 \mathrm{~g}$ in $5 \mathrm{~mL} \mathrm{CZY}$ broth added with $500 \mu \mathrm{g} / \mathrm{mL}$ tryptophan (Sigma, USA) in the dark at $30^{\circ} \mathrm{C}$ for 10 days. Two $\mathrm{mL}$ of the liquid culture were centrifuged for $10 \mathrm{~min}$ at $18000 \mathrm{~g}$. One $\mathrm{mL}$ of the supernatant was mixed with $50 \mu \mathrm{L}$ $10 \mathrm{mM}$ orthophosphoric acid and $2 \mathrm{~mL}$ of Salkowski reagent ( $1 \mathrm{~mL}$ of $0.5 \mathrm{M} \mathrm{FeCl}_{3}$ in $50 \mathrm{~mL}$ of $35 \% \mathrm{HClO}_{4}$ ). The tubes were incubated at room temperature for $30 \mathrm{~min}$. The development of pink color indicated the IAA production, which was quantified by spectrophotometer at $530 \mathrm{~nm}$. The experiment was repeated twice in three replicates.

\section{SOIL, R00T, AND RHIZOSPHERE COLONIZATION BY t-ZEA17I}

The transformed ZEA17I strain (t-ZEA17I) was grown on CZY medium containing $50 \mathrm{mg} / \mathrm{L}$ of apramycin at $24^{\circ} \mathrm{C}$ for 10 days. Spores were collected in 10\% sterile glycerol and filtered through two layers of gauze. The concentration was determined and the spore suspension was stored at $-20^{\circ} \mathrm{C}$. 


\section{Bulk soil colonization}

Prior to colonization studies, the presence of naturally occurring apramycin-resistant streptomycetes in non-sterilized Irish and Baltic peat-based growth substrate (Vigorplant, Italy) was assessed. A portion of the substrate was resuspended in sterile water and plated on water agar medium (WA) containing $15 \mathrm{~g} / \mathrm{L}$ agar, $25 \mathrm{mg} / \mathrm{L}$ nalidixic adic, $50 \mathrm{mg} / \mathrm{L}$ apramycin, $50 \mathrm{mg} / \mathrm{L}$ nystatin, and $50 \mathrm{mg} / \mathrm{L}$ cycloheximide. Plates were incubated for 7 days at $24^{\circ} \mathrm{C}$ and the presence of apramycin-resistant streptomycete colonies was visually checked.

The growth substrate was placed in a polystyrene seed tray $\left(48 \mathrm{~cm}^{3} / \mathrm{cell}\right)$ and watered with tap water. In every cell, t-ZEA17I was uniformly distributed on the top of the substrate adding $1 \mathrm{~mL}$ spore suspension $\left(1 \times 10^{7} \mathrm{CFU} / \mathrm{mL}\right)$. The growth substrate was incubated in a growth chamber $\left(24^{\circ} \mathrm{C}, 55 \%\right.$ relative humidity and $15 \mathrm{~h}$ photoperiod) and watered every $2-3$ days with tap water. $\mathrm{t}$-ZEA17I was re-isolated $4 \mathrm{~h}$ (day 0 ), 10, 20, and 30 days after inoculation (dai) in six replicates. The entire amount of growth substrate in the cell was collected and weighed. The substrate was mixed to homogenize the inoculum and divided in two identical parts. One part was incubated in the oven at $50^{\circ} \mathrm{C}$ and the dry weight was determined. The other part was stirred in sterilized water (1:10 substrate fresh w/v) for one hour and serial dilutions were plated on WA. Plates were incubated for 7 days at $24^{\circ} \mathrm{C}$ and streptomycete colonies were counted. The t-ZEA17I concentration was expressed as CFU/g of growth substrate dry weight.

\section{Plant inoculation}

Ice queen lettuce seedlings (Lactuca sativa var. capitata, Iceberg group, Semeurop, Italy) were grown in polystyrene seed trays, as described previously. Seeds were surface sterilized in $0.7 \%$ sodium hypochlorite for $5 \mathrm{~min}$ and rinsed three times in sterile water. Two methods were used to inoculate the t-ZEA17I strain. In the growth substrate inoculation method, $1 \mathrm{~mL}$ spore suspension $\left(1 \times 10^{7} \mathrm{CFU} / \mathrm{mL}\right)$ was uniformly distributed in every cell on the top of the growth substrate. In the seed coating method, 50 seeds were soaked in $1 \mathrm{~mL}$ of t-ZEA17I spore suspension $\left(1 \times 10^{7} \mathrm{CFU} / \mathrm{mL}\right)$ and left to dry under the laminar flow hood. One seed for each cell of the tray was sown and the seedlings were incubated and watered as described previously.

To determine the inoculum load t-ZEA17I was re-isolated from seeds and growth substrate after inoculum application. In case of the growth substrate inoculation method, the t-ZEA17I strain was re-isolated four hours after soil inoculation as described above for bulk soil, and its amount was expresses as CFU/g of growth substrate dry weight. For the seed coating method, 10 randomly collected seeds were incubated for $30 \mathrm{~min}$ in $1 \mathrm{~mL}$ of sterile $0.9 \% \mathrm{NaCl}$ and serial dilutions were plated on WA medium in six replicates. Following incubation at $24^{\circ} \mathrm{C}$ for 7 days the tZEA17I colonies were counted and the amount was expressed first as $\mathrm{CFU} /$ seed and then recalculated as $\mathrm{CFU} / \mathrm{g}$ of growth substrate dry weight.

\section{t-ZEA17I re-isolation from rhizosphere and root tissues}

The t-ZEA17I strain was re-isolated 10, 20, and 30 days after sowing from rhizosphere and root tissues of six lettuce seedlings, equal to number of replicates. Seedlings with root system were carefully taken off the cell and the bulk soil was removed by gently shaking the plants (Bulgarelli et al., 2012).

For the rhizosphere analysis, each seedling was cut at base and the roots were vortexed two times for $15 \mathrm{~s}$ in 1-3 mL (volume varying according to period of sampling) of sterilized $0.9 \% \mathrm{NaCl}$ and $0.02 \%$ Silwet L-77 (washing solution). The roots were removed and the suspension was filtered through a $300 \mu \mathrm{m}$ nylon mesh to obtain the rhizosphere soil and its dry weight was determined. The suspension was centrifuged at $10600 \mathrm{~g}$ for $10 \mathrm{~min}$ and the pellet was resuspended in $0.5-1.5 \mathrm{~mL}$ of washing solution and plated in serial dilutions on WA medium. The plates were incubated at $24^{\circ} \mathrm{C}$ for 7 days. The t-ZEA17I colonies were counted and the concentration was expressed as $\mathrm{CFU} / \mathrm{g}$ of rhizosphere dry weight.

For inner root tissues analysis, the roots were surface sterilized with propylene oxide for one hour (Sardi et al., 1992). Then, they were washed in washing solution and 1/10 of the total volume was plated on WA medium to verify the absence of contaminants. Subsequently the roots were finely homogenized in $1-3 \mathrm{~mL}$ washing solution, let to macerate for one hour and the suspension was plated in serial dilutions. The t-ZEA17I concentration was determined as described before and expressed as CFU/g of roots dry weight.

\section{STATISTICAL ANALYSES}

All analyses were done using R software, version R3.0.2. (R Core Team, 2013). The statistical differences between data of transformed and wild-type strains in S. sclerotiorum growth inhibition, sporulation, and IAA production were compared by a Student's $t$-test $(P=0.05)$. The percent data were arcsine root-squared transformed. The soil, root, and rhizosphere colonization data were submitted to ANOVA, followed by a Tukey post hoc test for multiple comparison $(P=0.05)$, using the TukeyC package (Faria et al., 2013).

\section{RESULTS}

\section{TRANSFORMATION OF Streptomyces spp. WITH PLASMID pIJ8641}

All six strains, including S. coelicolor A3(2) were transformed with the pIJ8641 plasmid harboring the EGFP gene under a constitutive promoter and apramycin resistance. Conjugation efficiency varied among strains: four strains, CX14W, SW06W, CX16W, and FT05W showed conjugation efficiency similar to $S$. coelicolor A3(2), while one strain, ZEA17I conjugated with lower efficiency (Table 1). The EGFP gene was detected in transformed strains (data not shown), and its expression was confirmed by fluorescence microscopy observing a strong green fluorescence in all transformants following exposition to fluorescent light (Figure 1), while the corresponding wild-type strains did not fluoresce.

\section{EFFECT OF THE TRANSFORMATION ON STRAIN FITNESS}

Following the transformation, the fitness of transformants was evaluated in terms of mycelium growth and sporulation, inhibition of S. sclerotiorum mycelium growth, and production of selected secondary metabolites. All the transformed strains showed similar mycelium growth and sporulation to their corresponding wild-type strains (Figure $\mathbf{2}$ - for simplicity, the growth 
Table 1 | Conjugation efficiencies of five Streptomyces spp. strains and S. coelicolor A3(2) with the plJ8641 plasmid.

\begin{tabular}{lcc}
\hline Strain & $\begin{array}{r}\text { Recipient strain } \\
\text { (CFU/mL) }\end{array}$ & $\begin{array}{r}\text { Conjugation efficiency } \\
\text { (CFU/recipient strain) }\end{array}$ \\
\hline S. coelicolor A3(2) & $1 \times 10^{8}$ & $9.10 \times 10^{-6}$ \\
CX14W & $1 \times 10^{8}$ & $4.64 \times 10^{-5}$ \\
CX16W & $1 \times 10^{10}$ & $6.88 \times 10^{-6}$ \\
FT05W & $1 \times 10^{9}$ & $1.60 \times 10^{-6}$ \\
SW06W & $1 \times 10^{8}$ & $3.13 \times 10^{-5}$ \\
ZEA17I & $1 \times 10^{9}$ & $5.81 \times 10^{-8}$ \\
\hline
\end{tabular}

curves for only two strains were reported, Table 2). The transformants inhibited S. sclerotiorum radial growth from 66 to $81 \%$, and no significant differences were observed between wild-type and transformed strains. Finally, no significant differences were detected in siderophore, auxin, chitinase production, and phosphate solubilization (Tables 2 and 3 ).

\section{COLONIZATION DYNAMICS OF THE TRANSFORMED ZEA17I IN BULK SOIL}

In this study, apramycin was used as a marker to identify the transformed t-ZEA17I strain. However, to be able to use it in greenhouse experiments, we first checked for the presence of naturally occurring apramycin-resistant Streptomyces spp. in the growth substrate, but none were detected. Therefore non-sterilized growth substrate was used in following experiments.

The colonization dynamics of t-ZEA17I in bulk soil showed that the initial inoculum, $1.16 \times 10^{8} \mathrm{CFU} / \mathrm{g}$ dry weight added to the soil, was recovered at $3.85 \times 10^{7} \mathrm{CFU} / \mathrm{g}$ dry weight four hours after inoculation ( 0 dai). The t-ZEA17I amount decreased significantly within the first 10 days and thereafter it remained stable up to 30 days at $2.18 \times 10^{4} \mathrm{CFU} / \mathrm{g}$ dry weight (Table 4).

\section{COLONIZATION OF LETTUCE RHIZOSPHERE AND INNER ROOT TISSUES BY THE TRANSFORMED ZEA17I}

The Streptomyces strain t-ZEA17I was inoculated with two different methods: as a spore suspension distributed on soil surface and as seed coating. The colonization dynamics of rhizosphere and
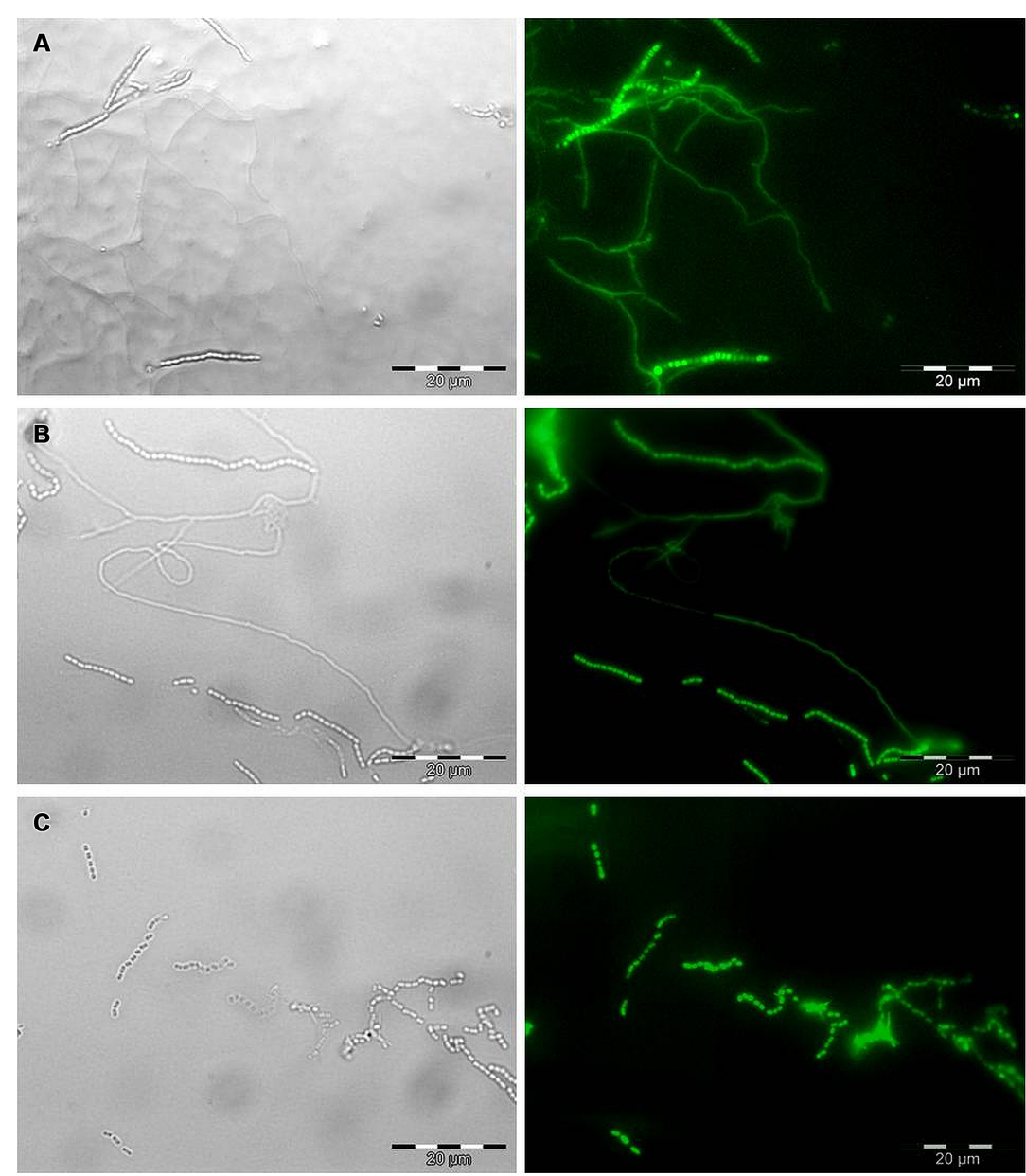

FIGURE 1 | Microscopic observation of EGFP expression in transformed Streptomyces strains by bright field (left) and epifluorescence microscopy (right). Mycelium and spore chains of (A) the strain t-ZEA17l, (B) the strain t-FT05W, and (C) spore chains of the strain t-CX16W. Scale bar, $20 \mu \mathrm{m}$. 

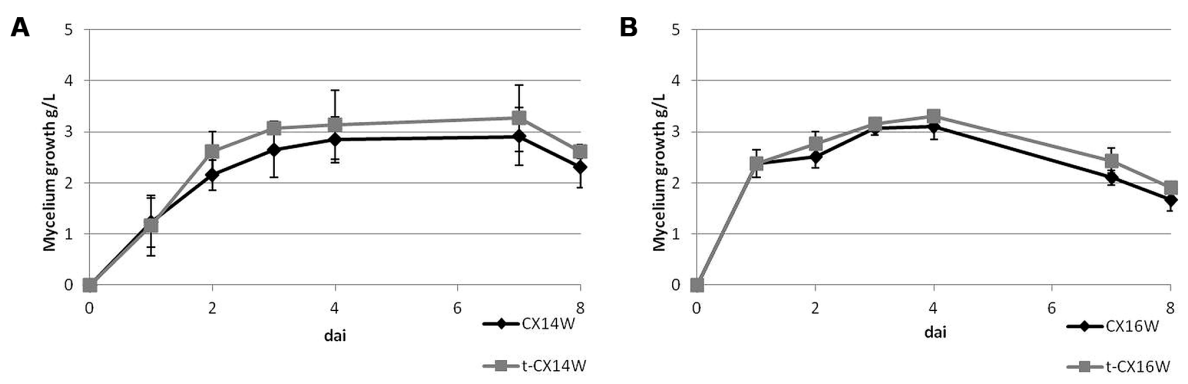

FIGURE 2 | Mycelium growth of the wild-type and transformed Streptomyces spp. strains, (A) CX14W and (B) CX16W. Vertical bars represent SE $(N=3)$.

Table 2 | Sporulation, auxin production, and inhibition of Sclerotinia sclerotiorum mycelium growth of the wild-type and transformed (t-) Streptomyces spp.

\begin{tabular}{|c|c|c|c|c|c|c|}
\hline Strain & \multicolumn{2}{|c|}{ Sporulation ( $\left.10^{9} \mathrm{CFU} / \mathrm{mL}\right)$} & \multicolumn{2}{|c|}{ Auxin production $(\mu \mathrm{g} / \mathrm{mL})$} & \multicolumn{2}{|c|}{ S. sclerotiorum inhibition (\%) } \\
\hline CX14W & $7.47 \pm 3.22^{1}$ & \multirow{2}{*}{$P^{2}=0.229$} & $5.82 \pm 0.44$ & \multirow{2}{*}{$P=0.278$} & $78.80 \pm 1.70$ & \multirow{2}{*}{$P=0.072$} \\
\hline $\mathrm{t}-\mathrm{C} \times 14 \mathrm{~W}$ & $6.80 \pm 4.91$ & & $5.11 \pm 0.35$ & & $73.00 \pm 2.28$ & \\
\hline CX16W & $4.23 \pm 6.58$ & \multirow{2}{*}{$P=0.178$} & $5.87 \pm 0.86$ & \multirow{2}{*}{$P=0.872$} & $68.99 \pm 0.98$ & \multirow{2}{*}{$P=0.091$} \\
\hline $\mathrm{t}-\mathrm{C} \times 16 \mathrm{~W}$ & $5.55 \pm 1.61$ & & $6.03 \pm 0.24$ & & $65.87 \pm 1.33$ & \\
\hline FT05W & $1.45 \pm 3.69$ & $P=0.242$ & $6.04 \pm 0.60$ & $P=0.207$ & $67.59 \pm 0.68$ & $P=0.684$ \\
\hline SW06W & $2.27 \pm 1.15$ & \multirow{2}{*}{$P=0.205$} & $7.32 \pm 0.66$ & \multirow{2}{*}{$P=0.588$} & $80.21 \pm 1.34$ & \multirow{2}{*}{$P=1.000$} \\
\hline t-SW06W & $0.78 \pm 1.67$ & & $6.88 \pm 0.28$ & & $80.21 \pm 1.34$ & \\
\hline ZEA17I & $0.47 \pm 0.23$ & \multirow{2}{*}{$P=0.417$} & $7.56 \pm 0.59$ & \multirow{2}{*}{$P=0.690$} & $74.80 \pm 1.76$ & \multirow{2}{*}{$P=0.069$} \\
\hline t-ZEA17I & $1.63 \pm 1.15$ & & $6.84 \pm 0.38$ & & $80.75 \pm 1.51$ & \\
\hline
\end{tabular}

${ }^{1}$ Mean value followed by SE. ${ }^{2}$ P-values of the Student's t-test pairwise comparisons.

Table 3 | Phosphate solubilization, chitinase, and siderophore production of the wild-type and transformed (t-) Streptomyces spp.

\begin{tabular}{lccc}
\hline Strain & $\begin{array}{c}\text { Phosphate } \\
\text { solubilization }\end{array}$ & $\begin{array}{c}\text { Chitinase } \\
\text { production }\end{array}$ & $\begin{array}{c}\text { Siderophore } \\
\text { production }\end{array}$ \\
\hline CX14W & +1 & + & + \\
t-CX14W & + & + & + \\
CX16W & + & + & + \\
t-CX16W & + & + & + \\
FT05W & + & + & - \\
t-FT05W & + & + & - \\
SW06W & + & + & - \\
t-SW06W & + & + & - \\
ZEA17I & + & + & - \\
t-ZEA17I & + & & + \\
\hline
\end{tabular}

${ }^{1}+$ indicates activity. - indicates no activity.

inner root tissues of lettuce seedlings differed between the two methods.

In the rhizosphere, the concentration of the t-ZEA17I strain remained similar to the inoculated amount during the first 20 dai with either method. When t-ZEA17I was distributed on top of the growth substrate, a significant increase in concentration 30 dai was observed. In the case of the seed coating, after a slight increase within the first 10 days, the final amount was not significantly different from the initial inoculum (Table 5).

Similarly, we studied the dynamics of t-ZEA17I colonization in the inner tissues of lettuce roots. First, we ruled out the possible external root contamination due to ineffective sterilization, and no Streptomyces colonies were detected. The t-ZEA17I strain was re-isolated from inner root tissues of surface-sterilized roots independently of the inoculation method, confirming its ability to endophytically colonize lettuce roots. The concentration of t-ZEA17I declined steadily through time, however, this reduction was not significant with either inoculation method (Table 6).

Finally, we compared the two inoculation methods to get a further insight into whether one of them could improve the survival and colonization rates of t-ZEA17I in lettuce rhizosphere and roots. In the rhizosphere, significantly more t-ZEA17I was re-isolated at all sampling times using the growth substrate inoculation rather than seed coating $(P=0.0037,0.0389$, and 0.0005 , for sampling time 10, 20, and 30 dai, respectively). Similarly, in roots, significantly higher concentration of t-ZEA17I was reisolated using the growth substrate inoculation at 20 and 30 dai 
Table 4 | Colonization dynamics in bulk soil by transformed Streptomyces ZEA17I.

\begin{tabular}{lcccc}
\hline Inoculation method & \multicolumn{3}{c}{ Bulk soil (CFU/g dry weight) } \\
\cline { 2 - 4 } & $\mathbf{0 ~ d a i}^{\mathbf{1}}$ & $\mathbf{1 0}$ dai & $\mathbf{2 0}$ dai & $\mathbf{3 0}$ dai \\
\hline Growth substrate & $3.85 \times 10^{7} \mathrm{a}^{2}$ & $1.25 \times 10^{4} \mathrm{~b}$ & $1.54 \times 10^{4} \mathrm{~b}$ & $2.18 \times 10^{4} \mathrm{~b}$ \\
\hline
\end{tabular}

${ }^{1}$ dai $=$ days after inoculation. ${ }^{2}$ Tukey post hoc test; means in a row with the same letters are not significantly different $(P=0.05)$.

Table 5 | Colonization dynamics of Lactuca sativa var. capitata rhizosphere by transformed Streptomyces ZEA17I strain according to two inoculation methods.

\begin{tabular}{lcccc}
\hline Inoculation method & \multicolumn{3}{c}{ Rhizosphere (CFU/g dry weight) } \\
\cline { 2 - 5 } & $\mathbf{0 ~ d a i}^{\mathbf{1}}$ & $\mathbf{1 0}$ dai & $\mathbf{2 0}$ dai & $\mathbf{3 0}$ dai \\
\hline Growth substrate & $2.51 \times 10^{6} \mathrm{~b}^{2}$ & $2.72 \times 10^{7} \mathrm{ab}$ & $3.07 \times 10^{7} \mathrm{a}$ & $3.80 \times 10^{7} \mathrm{a}$ \\
Seed coating & $1.28 \times 10^{6} \mathrm{ab}$ & $2.01 \times 10^{6} \mathrm{a}$ & $9.85 \times 10^{5} \mathrm{ab}$ & $1.19 \times 10^{5} \mathrm{~b}$ \\
\hline
\end{tabular}

${ }^{1}$ dai $=$ days after inoculation. ${ }^{2}$ Tukey post hoc test; means in a row with the same letters are not significantly different $(P=0.05)$.

Table 6 | Colonization dynamics of L. sativa var. capitata inner root tissues by transformed Streptomyces ZEA17I strain according to two inoculation methods.

\begin{tabular}{|c|c|c|c|}
\hline \multirow[t]{2}{*}{ Inoculation method } & \multicolumn{3}{|c|}{ Roots (CFU/g dry weight) } \\
\hline & 10 dai $^{1}$ & 20 dai & 30 dai \\
\hline Growth substrate & $1.94 \times 10^{7} \mathrm{~ns}^{2}$ & $1.45 \times 10^{6} \mathrm{~ns}$ & $2.36 \times 10^{5} \mathrm{~ns}$ \\
\hline Seed coating & $3.93 \times 10^{5} \mathrm{~ns}$ & $2.23 \times 10^{5} \mathrm{~ns}$ & $1.39 \times 10^{4} \mathrm{~ns}$ \\
\hline
\end{tabular}

${ }^{1}$ dai $=$ days after inoculation. ${ }^{2} n s$, ANOVA not significant $(P>0.05)$.

( $P=0.0415$ and $P=0.0604$, respectively). However, in spite of higher strain amounts present in roots using the growth substrate inoculation method, not all seedlings were colonized. Indeed, we failed to re-isolate t-ZEA17I from roots of three seedlings (one seedling at 20 dai and two seedlings at 30 dai), whereas, using the seed coating method, all roots were endophytically colonized.

\section{DISCUSSION}

Plant beneficial bacteria have a great potential in agriculture as PGPB and BCAs and reports about successful control of plant diseases are increasing. However, application of these microbial agents in field often fails to achieve the expected results, which could be due to lack of knowledge about their biology and interactions with the host plant, the pathogens, and other microorganisms in the rhizosphere. Therefore, there are increasing attempts to study these complex interactions that take place in the rhizosphere (Gamalero et al., 2003; Compant et al., 2010).

Our aim was to study spatio-temporal dynamics of colonization of lettuce roots and rhizosphere by Streptomyces spp. with biological control potential, to better understand if and how they inhabit the rhizosphere and colonize plant roots. We selected five
Streptomyces strains on the basis of their strong in vitro antagonism against the major soil-borne pathogen of horticultural crops, S. sclerotiorum (Bonaldi et al., 2014), and we transformed them with the pIJ8641 plasmid harboring apramycin resistance marker and EGFP gene under a strong constitutive promoter (Sun et al., 1999). The conjugation efficiency varied, and for most strains it was comparable to the reference strain S. coelicolor A3(2). The pIJ8641 plasmid integrates at the chromosomal attachment site for the temperate phage $\varphi \mathrm{C} 31$, which may result in disruption or alteration of fitness and biological activity of the transformed strains. Indeed, decrease or loss of biological activity was detected after GFP-transformation of various BCAs, e.g., Pseudomonas putida, Metschnikowia pulcherrima, or Clonostachys rosea (Nigro et al., 1999; Lübeck et al., 2002; Weyens et al., 2012). We compared several traits important for biological control and plant growth promotion of transformed and wild-type strains, before studying their interactions with the host plant. None of the transformed strains showed altered growth or sporulation, which could have conferred a disadvantage in plant root and rhizosphere colonization. All transformants retained the ability to suppress growth of S. sclerotiorum in vitro, therefore they will also be used for studying their interactions with the pathogen and the mechanisms of biological control in vivo. Moreover, we compared the expression of some of the most common traits involved in plant growth promotion and biological control (Brader et al., 2014), such as production of auxins, siderophores and lytic enzymes, and no change in performance between the wild type and the transformants was observed.

We chose the most promising transformed strain, t-ZEA17I, for pilot studies of lettuce roots and rhizosphere colonization. We intentionally used a non-sterile growth substrate to simulate competition with natural microflora and evaluate the competitiveness of the inoculated Streptomyces strain exploiting the apramycin resistance for its identification among soil microorganisms. In absence of the host plant, we confirmed that t-ZEA17I freely survives in soil, although we observed a sharp decrease in its density 
within the first 10 days after bulk soil inoculation. Similar dynamics for introduced microbial population in non-sterile soil are already known, attributed to scarcity of available nutrients and adverse biotic and abiotic factors (van Veen et al., 1997). However, following the initial fall in population density, the t-ZEA17I population remained stable for up to 30 days, probably establishing an equilibrium with the indigenous microflora as described previously (Yuan and Crawford, 1995; Merzaeva and Shirokikh, 2006). In the presence of the lettuce plant, we did not detect in the rhizosphere the initial rapid decrease in t-ZEA17I amount that was observed in bulk soil. On the contrary, its concentration augmented when applied directly on the growth substrate. It is possible that t-ZEA17I was chemoattracted to the rhizosphere of the growing seedling, where it quickly established a stable interaction with the host plant roots. Indeed, the presence of a host plant may greatly affect the survival of PGPB, as was observed, i.e., for the sharp decline in Azospirillum brasilense population after removal of inoculated plants (Bashan et al., 1995).

Different strategies are being used for studying BCAs and PGPB in the rhizosphere. Their localization in roots and seeds rely on microscopic tools exploiting fluorescent markers, which give a fundamental insight into the spatial distribution of the microorganism along and inside the growing root, but do not quantify the microbial amounts and their dynamics (Coombs and Franco, 2003; Olivain et al., 2006; Compant et al., 2010). Additionally, studying the dynamics of colonization by beneficial microorganisms exploits the strain identification mostly by natural or introduced antibiotic resistance and its quantification by dilution plating (Gamalero et al., 2003, 2005). Here, we quantified the t-ZEA17I in roots and rhizosphere through the introduced antibiotic resistance for its identification, to understand if it can inhabit soil in competitive concentrations in comparison to the indigenous microflora. t-ZEA17I was detected in the inner root tissues of growing seedlings already 10 days after inoculation at high concentrations. Indeed, Coombs and Franco (2003) demonstrated that the EGFP-tagged endophytic Streptomyces sp. strain EN27 rapidly colonizes the wheat embryo, as it was detected in developing roots as early as $24 \mathrm{~h}$ after inoculation. Re-isolation of t-ZEA17I from the rhizosphere and the inner tissues of surface-sterilized roots indicates that it is both rhizospheric and endophytic, although it is not known if its localization affects its potential for biocontrol and plant growth promotion. It has been hypothesized that endophytic bacteria form more stable interactions with plants, rather than rhizospheric or epiphytic bacteria (Compant et al., 2010; Malfanova et al., 2011).

Finally, we tested how different methods of inoculation influence the t-ZEA17I colonization ability. When it was distributed directly on the growth substrate, higher concentration was detected in roots, however, we could not re-isolate the strain from all inoculated plants. On the contrary, when the seed coating method was used, less propagules were recovered but all plants were endophytically colonized. It is possible that in case of seed coating, t-ZEA17I is more closely associated with the growing seedling, which increases its probability to internally colonize root tissues. In roots, we observed progressive decline in its concentration using either inoculation method. Although the total amount of t-ZEA17I increased at different sampling times (data not shown), the increase in lettuce root biomass was probably higher than the strain growth, thus resulting in lower strain concentration per $g$ of root. To ensure that t-ZEA17I colonizes roots in effective concentrations, and to prevent its decline to undetectable levels, studies assessing optimal amount of inoculum are needed. Moreover, it is possible that strains colonize only certain root zones (Gamalero et al., 2004, 2005). Therefore, further studies are needed to establish which zones of the plant roots are colonized by t-ZEA17I and ultimately how it interacts with the plant in presence of $S$. sclerotiorum, to evaluate its biological control activity in vivo.

\section{ACKNOWLEDGMENTS}

The authors thank prof. Flavia Marinelli (University of Insubria, Italy), for donor strain E. coli ET12567 and reference strain S. coelicolor A3(2) and Prof. Mervyn Bibb (John Innes Centre, UK), for kindly providing the plasmid pIJ8641. The authors also thank the reviewers for their constructive and useful comments that greatly improved the manuscript. This research was supported in part by research program "Dote ricerca applicata" funded by Lombardy Region and Sipcam Italia Spa.

\section{REFERENCES}

Aeron, A., Kumar, S., Pandey, P., and Maheshwari, D. K. (2011). "Emerging role of plant growth promoting rhizobacteria in agrobiology," in Bacteria in Agrobiology: Crop Ecosystems, ed. D. K. Maheshwari (Berlin: Springer), 1-36. doi: 10.1007/9783-642-18357-7_1

Bano, N., and Musarrat, J. (2003). Characterization of a new Pseudomonas aeruginosa strain NJ-15 as a potential biocontrol agent. Curr. Microbiol. 46, 0324-0328. doi: 10.1007/s00284-002-3857-8

Bashan, Y., Puente, M. E., Rodriguezmendoza, M. N., Toledo, G., Holguin, G., Ferreracerrato, R., etal. (1995). Survival of Azospirillum brasilense in the bulk soil and rhizosphere of 23 soil types. Appl. Environ. Microbiol. 61, 1938-1945.

Berg, G. (2009). Plant-microbe interactions promoting plant growth and health: perspectives for controlled use of microorganisms in agriculture. Appl. Microbiol. Biotechnol. 84, 11-18. doi: 10.1007/s00253-009-2092-7

Bonaldi, M., Kunova, A., Saracchi, M., Sardi, P., and Cortesi, P. (2014). Streptomycetes as biological control agents against basal drop. Acta Hortic. 1044, 313-318.

Bonaldi, M., Kunova, A., Sardi, P., Cortesi, P., and Saracchi, M. (2011). Streptomycetes as possible biocontrol agents against soil-borne pathogens. J. Plant Pathol. 93, S4.26-S4.27.

Brader, G., Compant, S., Mitter, B., Trognitz, F., and Sessitsch, A. (2014). Metabolic potential of endophytic bacteria. Curr. Opin. Biotechnol. 27, 30-37. doi: 10.1016/j.copbio.2013.09.012

Bric, J. M., Bostock, R. M., and Silverstone, S. E. (1991). Rapid in situ assay for indoleacetic acid production by bacteria immobilized on a nitrocellulose membrane. Appl. Environ. Microbiol. 57, 535-538.

Bulgarelli, D., Rott, M., Schlaeppi, K., Ver Loren Van Themaat, E., Ahmadinejad, N., Assenza, F., etal. (2012). Revealing structure and assembly cues for Arabidopsis root-inhabiting bacterial microbiota. Nature 488, 91-95. doi: 10.1038 /nature 11336

Cao, L., Qiu, Z., You, J., Tan, H., and Zhou, S. (2004). Isolation and characterization of endophytic Streptomyces strains from surface-sterilized tomato (Lycopersicon esculentum) roots. Lett. Appl. Microbiol. 39, 425-430. doi: 10.1111/j.1472-765X.2004.01606.x

Cao, Y., Zhang, Z., Ling, N., Yuan, Y., Zheng, X., Shen, B., et al. (2011). Bacillus subtilis SQR 9 can control Fusarium wilt in cucumber by colonizing plant roots. Biol. Fertility Soils 47, 495-506. doi: 10.1007/s00374-011-05562

Compant, S., Clement, C., and Sessitsch, A. (2010). Plant growth-promoting bacteria in the rhizo- and endosphere of plants: their role, colonization, mechanisms involved, and prospects for utilization. Soil. Biol. Biochem. 42, 669-678. doi: 10.1016/j.soilbio.2009.11.024 
Compant, S., Duffy, B., Nowak, J., Clement, C., and Barka, E. A. (2005). Use of plant growth-promoting bacteria for biocontrol of plant diseases: principles, mechanisms of action, and future prospects. Appl. Environ. Microbiol. 71, 49514959. doi: 10.1128/Aem.71.9.4951-4959.2005

Coombs, J. T., and Franco, C. M. M. (2003). Visualization of an endophytic Streptomyces species in wheat seed. Appl. Environ. Microbiol. 69, 4260-4262. doi 10.1128/Aem.69.7.4260-4262.2003

Coombs, J. T., Michelsen, P. P., and Franco, C. M. (2004). Evaluation of endophytic actinobacteria as antagonists of Gaeumannomyces graminis var. tritici in wheat. Biol. Control 29, 359-366. doi: 10.1016/j.biocontrol.2003.08.001

Errampalli, D., Leung, K., Cassidy, M. B., Kostrzynska, M., Blears, M., Lee, H., et al. (1999). Applications of the green fluorescent protein as a molecular marker in environmental microorganisms. J. Microbiol. Methods 35, 187-199. doi: 10.1016/S0167-7012(99)00024-X

Faria, J. C., Jelihovschi, E. G., and Allaman, I. B. (2013). Conventional Tukey Test. Ilheus: Test.UESC.

Gamalero, E., Lingua, G., Berta, G., and Lemanceau, P. (2003). Methods for studying root colonization by introduced beneficial bacteria. Agronomie 23, 407-418. doi: 10.1051/Agro:2003014

Gamalero, E., Lingua, G., Capri, F. G., Fusconi, A., Berta, G., and Lemanceau, P. (2004). Colonization pattern of primary tomato roots by Pseudomonas fluorescens A6RI characterized by dilution plating, flow cytometry, fluorescence, confocal, and scanning electron microscopy. FEMS Microbiol. Ecol. 48, 79-87. doi: 10.1016/j.femsec.2003.12.012

Gamalero, E., Lingua, G., Tombolini, R., Avidano, L., Pivato, B., and Berta, G. (2005). Colonization of tomato root seedling by Pseudomonas fluorescens 92rkG5: spatiotemporal dynamics, localization, organization, viability, and culturability. Microb. Ecol. 50, 289-297. doi: 10.1007/s00248-004-0149-9

Ghirardi, S., Dessaint, F., Mazurier, S., Corberand, T., Raaijmakers, J. M., Meyer, J. M., et al. (2012). Identification of traits shared by rhizosphere-competent strains of fluorescent pseudomonads. Microb. Ecol. 64, 725-737. doi: 10.1007/s00248012-0065-3

Glick, B. R. (2012). Plant growth-promoting bacteria: mechanisms and applications. Scientifica 2012, 15. doi: 10.6064/2012/963401

Grantcharova, N., Lustig, U., and Flardh, K. (2005). Dynamics of FtsZ assembly during sporulation in Streptomyces coelicolor A3(2). J. Bacteriol. 187, 3227-3237. doi: $10.1128 / \mathrm{Jb} .187 .3227 .3237 .2005$

Haas, J., Park, E.-C., and Seed, B. (1996). Codon usage limitation in the expression of HIV-1 envelope glycoprotein. Curr. Biol. 6, 315-324. doi: 10.1016/S09609822(02)00482-7

Hanahan, D. (1983). Studies on transformation of Escherichia coli with plasmids. J. Mol. Biol. 166, 557-580. doi: 10.1016/S0022-2836(83)80284-8

Hinsinger, P., Bengough, A. G., Vetterlein, D., and Young, I. (2009). Rhizosphere: biophysics, biogeochemistry and ecological relevance. Plant Soil 321, 117-152. doi: 10.1007/s11104-008-9885-9889

Hohmann, P., Jones, E. E., Hill, R. A., and Stewart, A. (2012). Ecological studies of the bio-inoculant Trichoderma hamatum LU592 in the root system of Pinus radiata. FEMS Microbiol. Ecol. 80, 709-721. doi: 10.1111/j.1574-6941.2012.01340.x

Hopwood, D. A. (2007). Streptomyces in Nature and Medicine: The Antibiotic Makers. Oxford: Oxford University Press New York.

Khamna, S., Yokota, A., and Lumyong, S. (2009). Actinomycetes isolated from medicinal plant rhizosphere soils: diversity and screening of antifungal compounds, indole-3-acetic acid and siderophore production. World J. Microbiol. Biotechnol. 25, 649-655. doi: 10.1007/s11274-008-9933-x

Kieser, T., Bibb, M. J., Buttner, M. J., Chater, K. F., and Hopwood, D. A. (2000). Practical Streptomyces Genetics. Norwich: The John Innes Foundation.

Krzyzanowska, D., Obuchowski, M., Bikowski, M., Rychlowski, M., and Jafra, S. (2012). Colonization of potato rhizosphere by GFP-tagged Bacillus subtilis MB73/2, Pseudomonas sp. P482 and Ochrobactrum sp. A44 shown on large sections of roots using enrichment sample preparation and confocal laser scanning microscopy. Sensors 12, 17608-17619. doi: 10.3390/S121 217608

Latour, X., Delorme, S., Mirleau, P., and Lemanceau, P. (2003). Identification of traits implicated in the rhizosphere competence of fluorescent pseudomonads: description of a strategy based on population and model strain studies. Agronomie 23, 397-405. doi: 10.1051/Agro:2003015

Loria, R., Kers, J., and Joshi, M. (2006). Evolution of plant pathogenicity in Streptomyces. Аnnu. Rev. Phytopathol. 44, 469-487. doi: 10.1146/annurev.phyto.44.032905.091147
Lu, Z. X., Tombolini, R., Woo, S., Zeilinger, S., Lorito, M., and Jansson, J. K. (2004), In vivo study of Trichoderma-pathogen-plant interactions, using constitutive and inducible green fluorescent protein reporter systems. Appl. Environ. Microbiol. 70, 3073-3081. doi: 10.1128/Aem.70.5.3073-3081.2004

Lübeck, M., Knudsen, I., Jensen, B., Thrane, U., Janvier, C., and Funck Jensen, D. (2002). GUS and GFP transformation of the biocontrol strain Clonostachys rosea IK726 and the use of these marker genes in ecological studies. Mycol. Res. 106, 815-826. doi: 10.1017/S095375620200607X

Lucas, X., Senger, C., Erxleben, A., Grüning, B. A., Döring, K., Mosch, J., et al. (2013). StreptomeDB: a resource for natural compounds isolated from Streptomyces species. Nucleic Acids Res. 41, D1130-D1136. doi: 10.1093/nar/gks1253

Lugtenberg, B. J., Chin-A-Woeng, T. C., and Bloemberg, G. (2002). Microbe-plant interactions: principles and mechanisms. Antonie Van Leeuwenhoek 81, 373-383. doi: 10.1023/a:1020596903142

Lugtenberg, B. J. J., Dekkers, L., and Bloemberg, G. V. (2001). Molecular determinants of rhizosphere colonization by Pseudomonas. Annu. Rev. Phytopathol. 39, 461-490. doi: 10.1146/annurev.phyto.39.1.461

Lugtenberg, B., and Kamilova, F. (2009). Plant-growth-promoting rhizobacteria. Annu. Rev. Microbiol. 63, 541-556. doi: 10.1146/annurev.micro.62.081307. 162918

Malfanova, N., Kamilova, F., Validov, S., Shcherbakov, A., Chebotar, V., Tikhonovich, I., et al. (2011). Characterization of Bacillus subtilis HC8, a novel plant-beneficial endophytic strain from giant hogweed. Microbial Biotechnol. 4, 523-532. doi: 10.1111/j.1751-7915.2011.00253.x

Merzaeva, O. V., and Shirokikh, I. G. (2006). Colonization of plant rhizosphere by actinomycetes of different genera. Microbiology 75, 226-230. doi: $10.1134 /$ S0026261706020184

Minuto, A., Spadaro, D., Garibaldi, A., and Gullino, M. L. (2006). Control of soilborne pathogens of tomato using a commercial formulation of Streptomyces griseoviridis and solarization. Crop Prot. 25, 468-475. doi: 10.1016/j.cropro.2005.08.001

Nautiyal, C. S. (1999). An efficient microbiological growth medium for screening phosphate solubilizing microorganisms. FEMS Microbiol. Lett. 170, 265-270. doi: 10.1111/j.1574-6968.1999.tb13383.x

Nigro, F., Finetti Sialer, M. M., and Gallitelli, D. (1999). Transformation of Metschnikowia pulcherrima 320, biocontrol agent of storage rot, with the green fluorescent protein gene. J. Plant Pathol. 205-208.

Olivain, C., Humbert, C., Nahalkova, J., Fatehi, J., L'haridon, F., and Alabouvette, C. (2006). Colonization of tomato root by pathogenic and nonpathogenic Fusarium oxysporum strains inoculated together and separately into the soil. Appl. Environ. Microbiol. 72, 1523-1531. doi: 10.1128/Aem.72.2.15231531.2006

Perez-Miranda, S., Cabirol, N., George-Tellez, R., Zamudio-Rivera, L. S., and Fernandez, F. J. (2007). O-CAS, a fast and universal method for siderophore detection. J. Microbiol. Methods 70, 127-131. doi: 10.1016/j.mimet.2007. 03.023

Petrolini, B., Quaroni, S., Saracchi, M., and Sardi, P. (1996). Studies on the streptomycete population inhabiting plant roots. Actinomycetes 7, 66-78.

Philippot, L., Raaijmakers, J. M., Lemanceau, P., and Van Der Putten, W. H. (2013). Going back to the roots: the microbial ecology of the rhizosphere. Nat. Rev. Microbiol. 11, 789-799. doi: 10.1038/Nrmicro3109

Prosser, J. I. (1994). Molecular marker systems for detection of geneticallyengineered microorganisms in the environment. Microbiology 140, 5-17. doi: 10.1099/13500872-140-1-5

R Core Team. (2013). R: A Language and Environment for Statistical Computing. (Vienna: R Foundation for Statistical Computing).

Raaijmakers, J. M., Paulitz, T. C., Steinberg, C., Alabouvette, C., and Moenne-Loccoz, Y. (2009). The rhizosphere: a playground and battlefield for soilborne pathogens and beneficial microorganisms. Plant Soil 321, 341-361. doi: 10.1007/s11104008-9568-6

Raaijmakers, J. M., Vlami, M., and De Souza, J. T. (2002). Antibiotic production by bacterial biocontrol agents. Antonie Van Leeuwenhoek International J. Gen. Mol. Microbiol. 81, 537-547. doi: 10.1023/A:1020501420831

Saima, M., Kuddus, M., Roohi, I., and Ahmad, Z. (2013). Isolation of novel chitinolytic bacteria and production optimization of extracellular chitinase. J. Genet. Eng. Biotechnol. 11, 39-46. doi: 10.1016/j.jgeb.2013.03.001

Sardi, P., Saracchi, M., Quaroni, S., Petrolini, B., Borgonovi, G. E., and Merli, S. (1992). Isolation of endophytic Streptomyces strains from surface-sterilized roots. Appl. Environ. Microbiol. 58, 2691-2693. 
Schwyn, B., and Neilands, J. B. (1987). Universal chemical-assay for the detection and determination of siderophores. Anal. Biochem. 160, 47-56. doi: 10.1016/00032697(87)90612-9

Seipke, R. F., Kaltenpoth, M., and Hutchings, M. I. (2012). Streptomyces as symbionts: an emerging and widespread theme? FEMS Microbiol. Rev. 36, 862-876. doi: 10.1111/j.1574-6976.2011.00313.x

Smith, S. E., and Smith, F. A. (2011). Roles of arbuscular mycorrhizas in plant nutrition and growth: new paradigms from cellular to ecosystem scales. Annu. Rev. Plant Biol. 62, 227-250. doi: 10.1146/annurev-arplant-042110103846

Sun, J. H., Kelemen, G. H., Fernandez-Abalos, J. M., and Bibb, M. J. (1999). Green fluorescent protein as a reporter for spatial and temporal gene expression in Streptomyces coelicolor A3(2). Microbiology 145, 2221-2227.

Tokala, R. K., Strap, J. L., Jung, C. M., Crawford, D. L., Salove, M. H., Deobald, L. A., et al. (2002). Novel plant-microbe rhizosphere interaction involving Streptomyces lydicus WYEC108 and the pea plant (Pisum sativum). Appl. Environ. Microbiol. 68, 2161-2171. doi: 10.1128/AEM.68.5.2161-2171.2002

van Veen, J. A., van Overbeek, L. S., and van Elsas, J. D. (1997). Fate and activity of microorganisms introduced into soil. Microbiol. Mol. Biol. Rev. 61, 121-135.

Watve, M., Tickoo, R., Jog, M., and Bhole, B. (2001). How many antibiotics are produced by the genus Streptomyces? Arch. Microbiol. 176, 386-390. doi: $10.1007 / \mathrm{s} 002030100345$

Weisburg, W. G., Barns, S. M., Pelletier, D. A., and Lane, D. J. (1991). 16s Ribosomal DNA amplification for phylogenetic study. J. Bacteriol. 173, 697-703.
Weyens, N., Boulet, J., Adriaensen, D., Timmermans, J.-P., Prinsen, E., Van Oevelen, S., et al. (2012). Contrasting colonization and plant growth promoting capacity between wild type and a gfp-derative of the endophyte Pseudomonas putida W619 in hybrid poplar. Plant Soil 356, 217-230. doi: 10.1007/s11104-011-0831-x

Yuan, W. M., and Crawford, D. L. (1995). Characterization of Streptomyces lydicus WYEC108 as a potential biocontrol agent against fungal root and seed rots. Appl. Environ. Microbiol. 61, 3119-3128.

Conflict of Interest Statement: The authors declare that the research was conducted in the absence of any commercial or financial relationships that could be construed as a potential conflict of interest.

Received: 13 November 2014; accepted: 08 January 2015; published online: 06 February 2015.

Citation: Bonaldi M, Chen X, Kunova A, Pizzatti C, Saracchi M and Cortesi P (2015) Colonization of lettuce rhizosphere and roots by tagged Streptomyces. Front. Microbiol. 6:25. doi: 10.3389/fmicb.2015.00025

This article was submitted to Plant-Microbe Interaction, a section of the journal Frontiers in Microbiology.

Copyright (C) 2015 Bonaldi, Chen, Kunova, Pizzatti, Saracchi and Cortesi. This is an open-access article distributed under the terms of the Creative Commons Attribution License (CC BY). The use, distribution or reproduction in other forums is permitted, provided the original author(s) or licensor are credited and that the original publication in this journal is cited, in accordance with accepted academic practice. No use, distribution or reproduction is permitted which does not comply with these terms. 